\title{
BMJ Open Taste test using an edible taste film kit: a randomised controlled trial
}

\author{
Ji-sun Kim, ${ }^{1}$ Dong-Hyun Kim, ${ }^{2}$ Eun-ju Jeon, ${ }^{2}$ Byung Guk Kim, ${ }^{1}$ Jeongjun $Y u,{ }^{3}$ \\ Hyun-II Shin ${ }^{2}$
}

To cite: Kim J, Kim D-H, Jeon E, et al. Taste test using an edible taste film kit: a randomised controlled trial. BMJ Open 2019;9:e029077. doi:10.1136/ bmjopen-2019-029077

- Prepublication history and additional material for this paper are available online. To view these files, please visit the journal online (http://dx.doi. org/10.1136/bmjopen-2019029077).

Received 11 January 2019 Revised 31 August 2019 Accepted 13 September 2019

D) Check for updates

(c) Author(s) (or their employer(s)) 2019. Re-use permitted under CC BY-NC. No commercial re-use. See rights and permissions. Published by BMJ.

${ }^{1}$ Otorhinolaryngology-Head and Neck Surgery, Eunpyeong St. Mary's Hospital, College of Medicine, The Catholic University of Korea, Seoul, The Republic of Korea

${ }^{2}$ Otorhinolaryngology-Head and Neck Surgery, Incheon St. Mary's Hospital, College of Medicine, The Catholic University of Korea, Seoul, The Republic of Korea

${ }^{3}$ Ancors R\&D Center, Seoul, The Republic of Korea

Correspondence to Dr Dong-Hyun Kim; monolithkim@catholic.ac.kr

\section{ABSTRACT}

Objectives We developed an edible taste film test that can be stored easily as a kit. This study was conducted to confirm the agreement between the results of the edible taste film kit test and the conventional taste solution test. Design Prospective, randomised, controlled trial. Setting Single tertiary hospital.

Participants Sixty-two healthy volunteers with no selfdescribed taste problems.

Interventions A randomisation scheme was used to determine the order of use of the edible taste film kit and the taste solution test for each subject. The taste solution test was performed using a cotton swab. In the taste film kit test, an edible taste film was placed on the tongue, and the subject detected the taste after the film was dissolved by saliva.

Outcome measures For each test, we measured the taste identification threshold, taste detection time and total test time.

Results We confirmed the consistency of the taste identification thresholds of the two tests, and the results were consistent with each other except for the bitter taste results, which used coffee in the edible taste film kit and quinine in the taste solution test. Although the detection time for each taste quality was faster for the taste solution test, the mean total time was significantly shorter for the taste film kit test than for the taste solution test (6.16 \pm 2.27 min vs $7.04 \pm 1.98 \mathrm{~min}$, respectively; $p=0.004$ ) Conclusions The edible taste film kit along with the taste solution test will be useful for quantitative taste testing. Trial registration number KCT0002865.

\section{INTRODUCTION}

As people have become more interested in the quality of life, it has become important to enjoy the taste of food. With the increase in average life span resulting from advances in medical care, increased use of medications and the incidence rates of trauma and systemic damage have contributed to disorders of taste. ${ }^{1-5}$ Taste disorders can also be caused by operations commonly performed in otolaryngology departments, such as middle ear surgery, tonsillectomy and oropharyngeal surgery. ${ }^{6}$ Taste dysfunction can change the type and amount of food consumed and may reduce food satisfaction. Long-lasting or severe impairment of taste function can cause mental stress, nutritional imbalances
Strengths and limitations of this study

- This study includes information about the process for making a new, edible taste film kit and compares the kit with taste solutions used for taste testing.

- This study was intended to improve the reproducibility of the taste test using food ingredients that are accessible in real life.

- We confirmed the validity of the newly developed taste test in participants with normal taste function.

- The outcome measures were the taste identification threshold, taste detection time, and total test time.

- The results of this study did not have the parameters to quantify the benefits of the newly developed taste test related to contamination and concentration changes.

and eating disorders. ${ }^{8}$ Therefore, in these situations, the diagnosis of taste dysfunction is becoming more important.

Various tests are used to assess taste function. Tests using taste solutions are common; these tests comprise either a whole-mouth stimulation method or a regional method in which the taste solution is applied to a portion of the tongue. Although the taste solution tests are available at various concentrations that can be used for quantitative testing, the taste solution may become contaminated or its concentration may change over time. In addition, a mediator material, such as a filter paper disc, is needed to deliver a defined amount of the taste solution to the tongue or mouth. Therefore, we intended to develop an edible taste film kit as a new taste test to overcome these drawbacks of taste testing using solution.

The primary purpose of this study was to examine whether the edible taste film kit test is useful as a test of taste function. We determined whether the taste identification thresholds of the edible taste film kit test are similar to those of the conventional taste solution test when used in actual practice. The secondary purpose of this study was to compare the taste detection time and total test time of the two test methods. In addition, 
Table 1 Taste qualities and concentration series for the taste solution test and edible taste film kit test

\begin{tabular}{llllll}
\hline Taste quality & No. 1 & No. 2 & No. 3 & No. 4 & No. 5 \\
\hline Sweet & 0.003 & 0.025 & 0.1 & 0.2 & 0.8 \\
Salty & 0.003 & 0.0125 & 0.05 & 0.1 & 0.2 \\
Sour & 0.0002 & 0.002 & 0.02 & 0.04 & 0.08 \\
Bitter & 0.00001 & 0.0002 & 0.001 & 0.005 & 0.04 \\
\hline
\end{tabular}

Taste substances in the taste solution test included sucrose (sweet), $\mathrm{NaCl}$ (salty), tartaric acid (sour) and quinine $\mathrm{HCl}$ (bitter). Taste substances in the edible taste film kit test included sucrose (sweet), $\mathrm{NaCl}$ (salty), tartaric acid (sour) and instant coffee (bitter). The values are expressed as $\mathrm{g} / \mathrm{mL}$.

we investigated whether coffee, a food ingredient, could replace quinine $\mathrm{HCl}$, which is commonly used in tests for bitter taste. The full study protocol is available as a online supplement file.

\section{METHODS}

\section{Preparation of taste solutions}

We prepared taste solutions of each basic taste quality at five concentrations according to the previously published, most commonly used taste solution test (table 1$){ }^{9}$

\section{Manufacture of the edible taste film kit}

Water-soluble polymers were used as film-forming agents that could be dissolved by saliva in the mouth. The water-soluble polymers included pullulan $(\alpha-1,4 ; \alpha-1,6-$ glucan) (Hayashibara Co, Okayama, Japan) and sugar ester (Mitsubishi Chemical Foods Co, Tokyo, Japan). Pullulan is an edible thickener that can be made into films and be used as a food coating that inhibits oxidation and corrosion because of its low oxygen permeability. ${ }^{10}$ Amphiphilic sugar ester was used as an emulsifier to allow the components of the aqueous solution to mix well. ${ }^{11}$ After pullulan was dissolved completely in distilled water at $60^{\circ} \mathrm{C}-80^{\circ} \mathrm{C}$, the sugar ester and the ingredients for each taste were added. Pullulan $(25 \mathrm{mg})$ and emulsifier $(0.9$ $\mathrm{mg}$ ) per $100 \mathrm{~mL}$ of total solution were added. Sucrose (CheilJedang Co, Seoul, Korea), NaCl (Hanju Co, Ulsan, Korea), tartaric acid (Sigma Chemical Co, St. Louis, MO, USA) or instant coffee (Dongsuh Co, Seoul, Korea) were added at five different concentrations (table 1). To form the film, these solutions were thinly coated on a flat, sterilised pan with a constant thickness of 150-200 $\mu \mathrm{m}$, and dried in a drying oven at $50^{\circ} \mathrm{C}-60^{\circ} \mathrm{C}$ for $2-3$ hours. The thickness of the film after drying was $40-50 \mu \mathrm{m}$. The moulded film was aged for 1-10 days at a relative humidity of $50 \%-70 \%$ and then adjusted to have a water content of $10 \%-14 \%$. The film (figure 1A) was cut into regular-sized pieces $(2 \times 1.5 \mathrm{~cm})$ and packed into edible taste film kits (figure 1B). Table 1 lists the taste substances and their concentrations in each edible taste film kit.

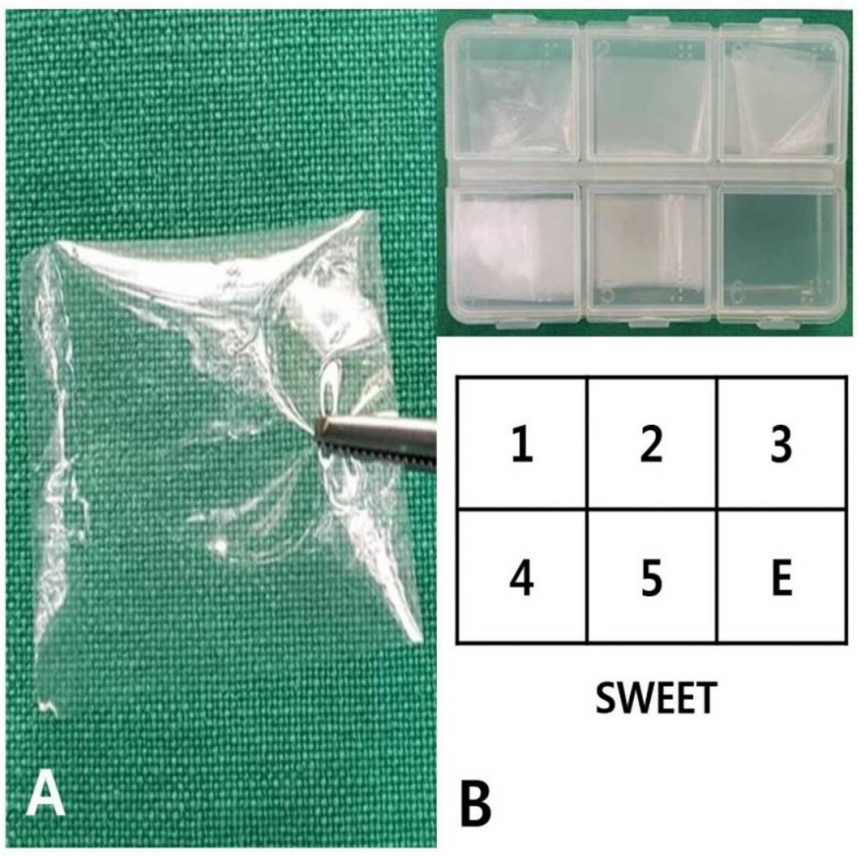

Figure 1 Edible taste film kit test. (A) Edible taste film, which measures $2 \times 1.5 \mathrm{~cm}$ and is $40-50 \mu \mathrm{m}$ thick. (B) An actual sweet edible taste film kit. The edible films are stacked according to concentration. The schematic shows concentrations 1-5. E indicates empty.

\section{Subjects}

This prospective study was conducted in the department of otorhinolaryngology of a single tertiary hospital. Between March 2016 and November 2017, we included healthy adult participants who had no self-reported problems with taste. The exclusion criteria were: (1) history of smoking, (2) diabetes, (3) history of neurological disorders, (4) history of middle ear surgery, (5) abnormal oral lesions or (6) dental treatment within the previous 48 hours.

The sample size was calculated using a formula for an equivalence trial to verify that the results of the tests using the conventional solution and the new edible taste film kit were equivalent for the identification of taste thresholds. The confidence level was $95 \%$ and the power of detection was $80 \%$. The mean difference between two groups was set to zero, and a mean difference between the thresholds within 0.5 was considered non-significant. In a pilot study that included 25 subjects, we determined the SD of the identification threshold for each taste, and the number of subjects was determined as the maximum value of the sample size for each taste. More information about this is provided in the online supplement file.

\section{Participants and public involvement}

The participants and the public were not involved in the design of the study. The general results without personal information will be disseminated as needed. Participants were recruited through advertisements posted on the hospital's bulletin board. Participants who met the inclusion criteria were informed of all procedures involved in 


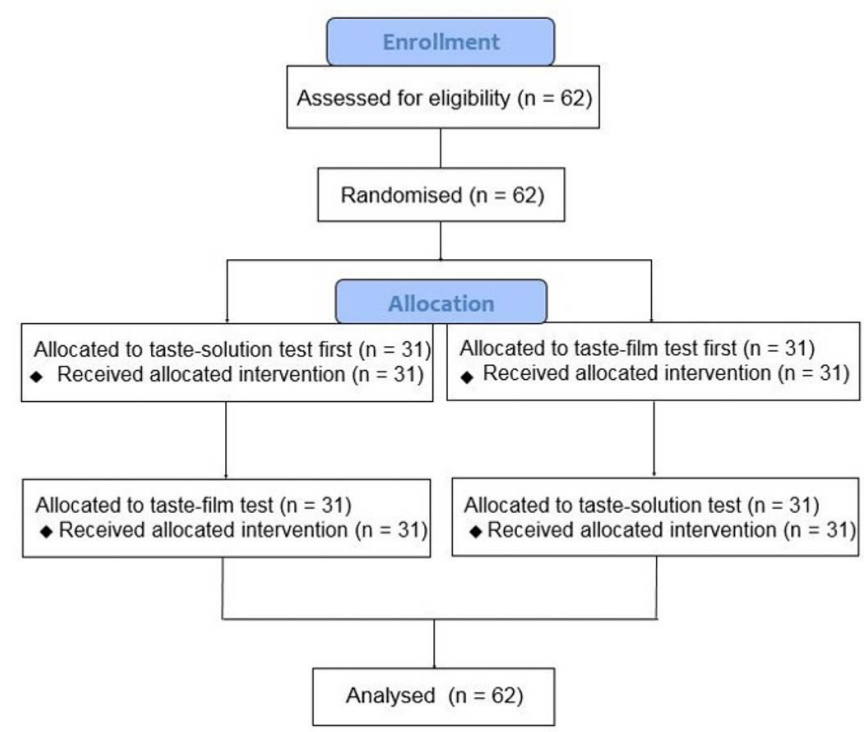

Figure 2 Study flow diagram.

the clinical trial and signed the informed consent form. The informed consent form noted that the principal investigator was responsible for any problems that might arise in this clinical trial.

\section{Methods of taste testing}

To reduce bias in the test order, a randomisation scheme was generated before the study using the website Randomization.com (http://www.randomization.com) and was used to determine the order of the edible taste film kit and the taste solution test for each subject. Sixty-two subjects were randomly assigned to a group, and there were no dropouts after the initial randomisation (figure 2).

The taste solution test was performed using six separate regions on the left and right sides of the tongue: the sweet taste on the tip of the tongue, the sour and salty tastes on the sides of the tongue and the bitter taste on the posterior one-third of the tongue. The examiner moistened a cotton swab with the taste solution and gently stimulated the subject's tongue. The subject then selected the perceived taste on a written index table. Salty, sour and sweet tastes were examined in random order, and the bitter taste was tested last. The taste solution test was performed using the same five sequential concentrations-from the lowest to highest concentration-as the film test. After the test for one taste was completed on the left and right sides of the tongue, the mouth was rinsed with water and then tested for another taste. In the edible taste film kit test, an edible taste film was placed on the middle portion of the tongue using forceps, and the subjects sensed the taste after the film was dissolved by saliva. The subsequent process was the same as for the taste solution test.

For each test, the primary outcome measure was the taste identification threshold, which is the lowest concentration at which a taste is recognised and correctly determined. The detection time for each taste and the total test time were measured as secondary outcome measures.

\section{Statistical analysis}

IBM SPSS Statistics (V.21.0, IBM Corp.) software was used for statistical analysis. The mean and SD were used to describe variables. The assumption of normality was checked using the Kolmogorov-Smirnov test. Agreement between the results of the two tests was examined using the kappa coefficient. A Wilcoxon matched-pairs signedrank test or a paired t-test was used to identify differences in each variable between tests. A p value $<0.05$ was considered significant. Cronbach's alpha was used to assess the internal consistency as a test of reliability.

\section{RESULTS}

Of the 62 subjects enrolled in this study, 34 were men and 28 were women. Their mean ages were $30.1 \pm 3.9$ years for men (23-45 years) and $31.9 \pm 8.2$ years for women $(22-55$ years). Age did not differ significantly between men and women $(\mathrm{p}=0.29)$.

Tests of the agreement between the taste identification thresholds of the solution test and the film test showed consistent results between tests except for the bitter taste, which used coffee in the taste film instead of quinine in the taste solution (table 2).

The identification threshold of sweet, sour and salty tastes differed between tests even though the same substance was used in both tests. The average identification thresholds for sweetness, sourness and salt were significantly higher in the film test than in the solution test. However, the average identification threshold for bitterness was significantly higher in the solution test using quinine $\mathrm{HCl}$ than in the film test using coffee. Cronbach's alpha was 0.783 (95\% CI, 0.690, 0.856). For each taste, the detection time was significantly longer in the taste film kit test. However, the average total test time was $6.16 \mathrm{~min}$ for the taste film kit test, which was significantly shorter than the 7.04 min for the taste solution test (table 3).

\section{DISCUSSION}

When the same tastants were used, the taste identification thresholds agreed between the edible taste film kit test and the taste solution test. The total test time was significantly less for the edible taste film kit test than for the taste solution test using a cotton swab. These findings suggest that the edible taste film kit test can be used clinically as a substitute for the taste solution test. The test results were not in agreement for coffee used instead of quinine as the bitter tastant in the taste film test; however, the identification thresholds for the two tests were similar. These results suggest that coffee may be an appropriate tastant for testing the bitter taste. 
Table 2 Agreement between the taste identification thresholds in the taste solution test and in the taste film kit test

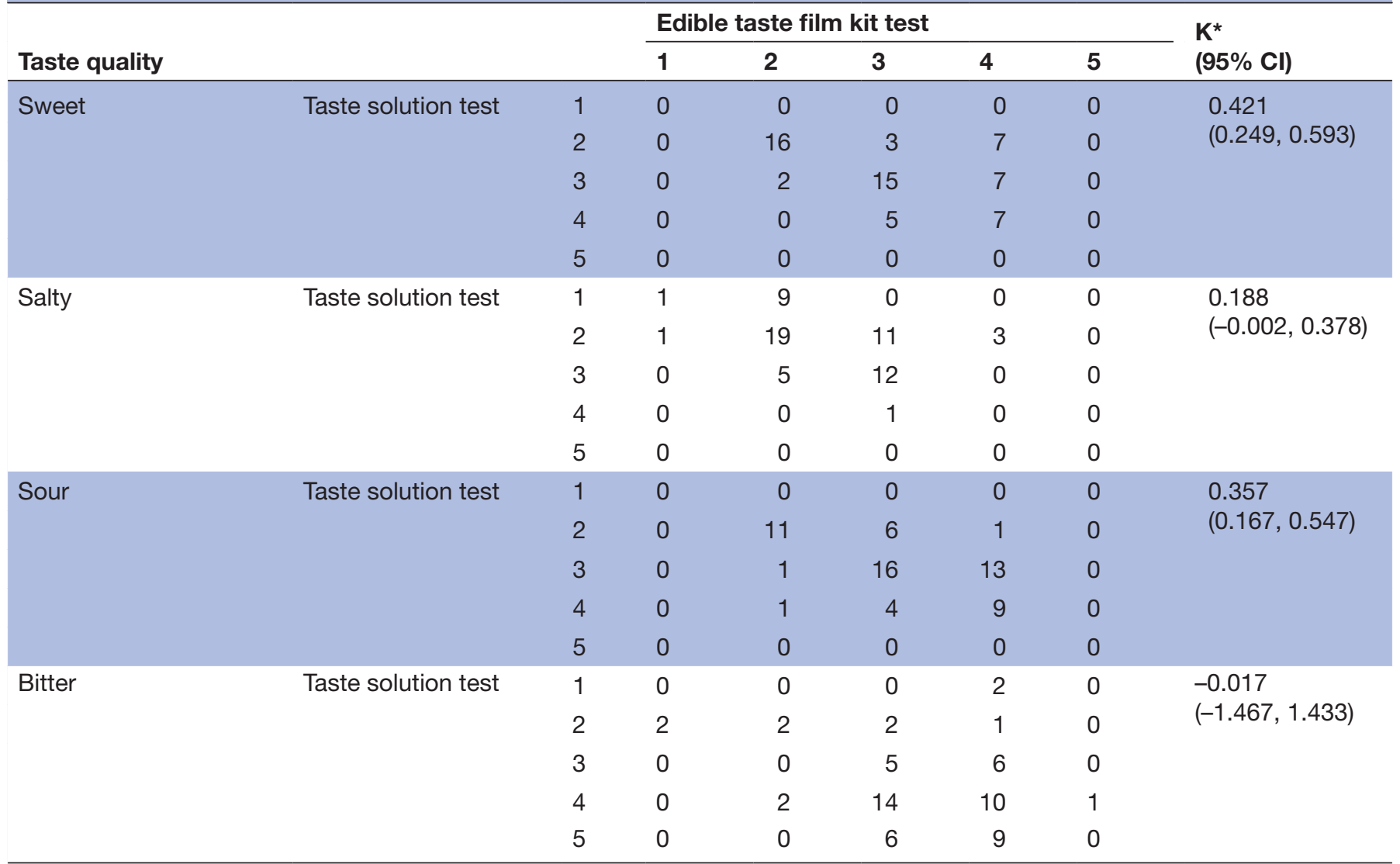

${ }^{*} \mathrm{~K}=$ Kappa agreement coefficient.

Taste is detected by specialised taste receptor cells that are localised in taste buds. These taste buds are found mostly in the papillae of the tongue but are also present in the pharynx, larynx and soft palate. ${ }^{12}$ Testing to determine whether a taste disorder is present requires a comprehensive evaluation of the tongue as well as various other areas responsible for taste detection. The conventional wholemouth test using a taste solution has the advantage of being quick and easy, but has possible side effects, such as vomiting, when used at high concentrations, which cause excessive stimulation. On the other hand, the regional test using a mediator such as a filter paper disc enables

Table 3 Comparison of taste detection time, total test time and taste identification thresholds between the taste solution test and the taste film kit test

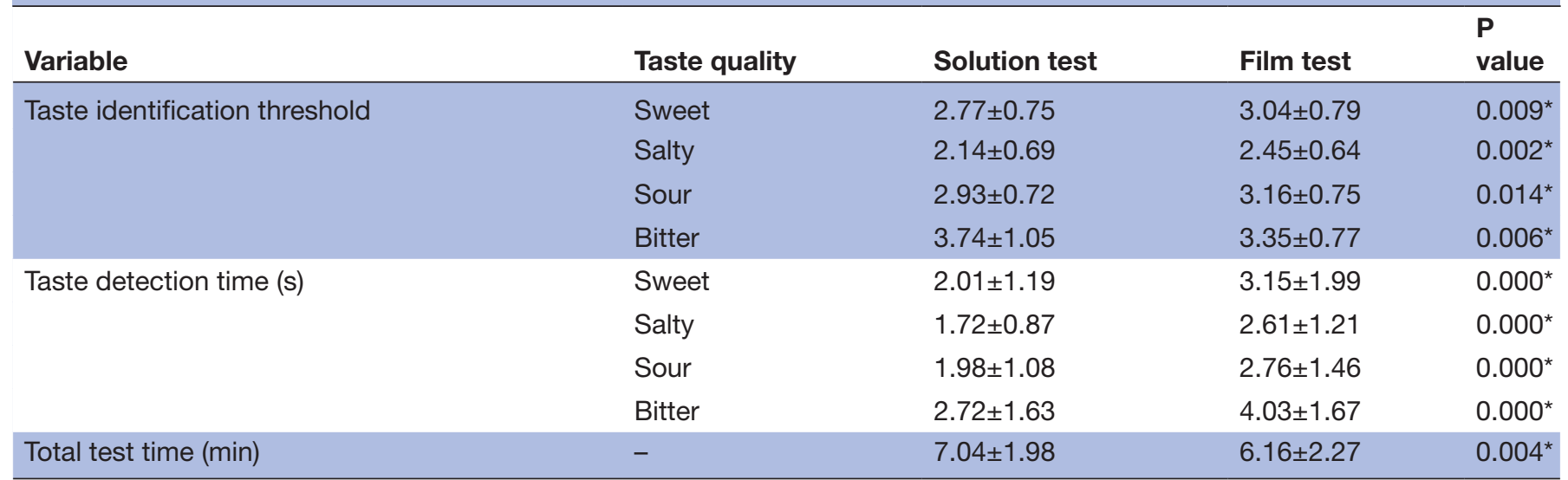

All data are expressed as the mean \pm SD.

The $\mathrm{p}$ values were assessed using the Wilcoxon matched-pairs signed-rank test (taste identification threshold and taste detection time) or paired t-test (total test time).

${ }^{*} p<0.05$. 
qualitative and quantitative testing and can avoid excessive stimulation. However, it is difficult to stimulate other taste buds in the oral cavity simultaneously except for those of the tongue. We devised an edible taste film kit as a method for stimulating the whole mouth, and this test has the quantitative and qualitative characteristics of a regional test using a mediator. The edible film could be made in a standardised size, such as a filter paper disc, placed on the middle of the tongue, and then dissolved by saliva to stimulate the whole mouth.

We compared our new taste test with the most frequently used taste solution test in a practical setting. Shortening the total test time while producing the same results would be useful for reducing the subject's burden during the test and increasing the efficiency of the test. In this study, the detection time for each basic taste was significantly shorter in the taste solution test than in the edible taste film kit test. This was probably because the taste solution diffused to the taste receptors faster given that the edible film needs time to be dissolved by saliva and to spread to the taste buds. The taste solution test was performed in six areas on both sides of the tongue, whereas the edible taste film kit test was performed in a single process by placing the film on the middle of the tongue. The total test time was, therefore, shorter for the edible taste film kit test than for the taste solution test. These findings suggest that the edible taste film kit test may be helpful for reducing the total time for taste testing in patients.

Quinine is a widely used drug but has side effects such as thrombocytopaenia and photosensitivity at certain concentrations. ${ }^{13}{ }^{14}$ No side effects of quinine have been reported in taste testing, but we replaced quinine with coffee to make the taste test safer. We also tried to improve the reproducibility of the bitter taste by using a more accessible food ingredient. We think that the different tastants used in the two tests may have caused differences in the bitter taste thresholds. Because the bitter taste threshold was lower for the taste film kit test, which used coffee, than for the taste solution test, which used quinine, we suggest that coffee is useful as a bitter tastant in taste testing. Only a small amount of coffee was added to the taste film, and the scent of the coffee was removed during the manufacturing process, so the film containing the coffee could not be distinguished from the other edible taste films by smell. Future studies using coffee should consider that higher concentrations of coffee may produce a scent. In addition, if the colour of the edible taste film intensifies as the coffee concentration becomes higher, it is possible that information about the taste concentration can be obtained in advance by inspecting the colour of the film before the test. Addition of artificial colouring to edible taste films may help to reduce or eliminate differences in the colour of the taste film. Further studies on the effect of film colour on the results of taste tests are needed.

Electrogustometry has long been used to diagnose taste dysfunction. It allows quantitative taste testing in localised areas by adjusting the amount of current, but qualitative testing of the four basic tastes is not possible. In addition, electrogustometry requires a longer time than other tests. In a solution-based taste test, the solution must be kept fresh and a mediator is needed to deliver a defined amount of solution to the test site. Some methods use mediators such as paper discs or taste strips to deliver the taste solution conveniently. ${ }^{915} 16$ However, these methods cannot solve the problems that the properties of the taste solutions change over time and that the results of the tests may vary depending on the examiner, methods and substances used. One study reported that the results of a taste solution test differed according to the placement of the taste strip on the tongue. ${ }^{17}$ In addition, mediators become hazardous waste.

Studies have introduced taste items in edible and solid forms, as in the edible taste film used in our kit. One study used tasting tablets with a diameter of $4 \mathrm{~mm}$ to deliver the taste,${ }^{18}$ but a pair of tweezers was needed to place these tablets on the tongue. Because of the tablets' small size, we speculate that this procedure would not be easy and that the tablets would be difficult to dissolve with saliva. Another study tested $15 \mathrm{~mm}$ cubes made of gelatin. ${ }^{19} \mathrm{In}$ that study, the authors emphasised that mastication was important for taste and that they had excluded participants with no teeth or with temporomandibular disorders. However, the edible taste film kit test used in our study is suited for such participants. Another study used a taste test using an edible taste strip made mainly of pullulan, ${ }^{20}$ but the proportions of materials used in this strip differed from those of our edible taste film. Our edible taste film could be stored easily in the kit and allowed quantitative taste testing that reflected the five graded concentrations of the taste solution test.

Previous studies of taste function in children or older adults with neurological disorders have used taste solution tests. ${ }^{21} 22 \mathrm{~A}$ test that requires patients to extend the tongue repeatedly may cause dryness of the tongue or activate gag reflexes. It is also difficult and time-consuming to perform the taste solution test in patients with disability or poor concentration. By contrast, the edible taste film kit can be used to test taste function in a variety of patients regardless of the site of testing.

Saliva dissolves taste stimuli and transfers them to taste receptors localised in taste buds. Saliva also maintains the sensitivity of taste cells. ${ }^{23}$ Taste dysfunction may occur even if the taste receptors are normal in people with impairment of the quality or total amount of secreted saliva. The edible taste film is dissolved in the mouth by saliva and movement of the tongue, which is similar to the process used during normal food intake. Although the edible taste film kit test cannot be used to evaluate saliva directly, abnormal salivation may be identified based on the results of the test. For example, an abnormally prolonged detection time in the edible taste film kit test may be used to screen for diseases such as Sjögren's syndrome. On the other hand, it may be difficult to identify qualitative taste function in patients with poor salivation, which is a limitation of the edible taste film kit test. 
In our study, the taste solution test involved six separate regions of the tongue. Taste buds in the oral cavity have similar functions, but there are subtle regional differences in sensitivity to compounds on the tongue surface. The 'tongue map' theory, which defines distinct areas of sweet, bitter, salty and sour, has been questioned recently. ${ }^{24}{ }^{25}$ The solution test method used in this study may need improvement. Another limitation of this study is that we did not try to quantify the benefits of a film kit in terms of contamination and changes in concentration. However, the taste film kit can be stored at room temperature without refrigeration. Additional research that includes parameters to assess contamination, changes in concentration and the test-retest reliability are needed to demonstrate objectively the benefits of the taste film kit.

There is no standard concentration of coffee for the bitter taste test, so we chose a coffee concentration in the edible taste film kit test that was the same as the quinine concentration in the conventional taste solution test. Further studies on the appropriate concentration of coffee for bitter taste tests are needed. Moreover, we used only pullulan, sugar ester and each tastant as ingredients of the taste film in this study. However, other film-forming water-soluble polymers including gelatin, cellulose, hydroxycellulose, starch and gum arabic may be used. In addition, microcrystalline cellulose, cellulose polymer, magnesium carbonate and calcium carbonate can also be used to reduce the slippery properties of the film and to serve as the skeleton of the film. These materials reduce adhesion between films and control the melting rate of the film in the mouth. Future studies of these substances are needed to develop a taste film kit with more useful properties for clinical use.

\section{CONCLUSION}

The edible taste film kit test may provide a new quantitative taste test for use with the taste solution test and may be helpful for reducing the total time required for testing. Coffee may be used as a bitter tastant instead of quinine, but further studies are needed to confirm this.

Contributors D-HK designed the study, performed the randomisation, analysed and interpreted the data, and drafted the manuscript, and is the guarantor. J-sK drafted the manuscript, interpreted the data and revised the manuscript. E-jJ, BGK, JY and $\mathrm{H}$-IS performed the experiments. All authors approved the submitted version of the manuscript.

Funding This work was supported by a grant from the Catholic Medical Center Research Foundation made in the program year of 2015 (552014B000100239).

Competing interests None declared.

Patient consent for publication Not required.

Ethics approval This study was conducted according to the principles of the Declaration of Helsinki and was approved by the Institutional Review Board (OC16EIS0149).

Provenance and peer review Not commissioned; externally peer reviewed. Data availability statement Data are available upon reasonable request.
Open access This is an open access article distributed in accordance with the Creative Commons Attribution Non Commercial (CC BY-NC 4.0) license, which permits others to distribute, remix, adapt, build upon this work non-commercially, and license their derivative works on different terms, provided the original work is properly cited, appropriate credit is given, any changes made indicated, and the use is non-commercial. See: http://creativecommons.org/licenses/by-nc/4.0/.

\section{REFERENCES}

1. Doty RL, Shah M, Bromley SM. Drug-Induced taste disorders. Drug Saf 2008;31:199-215.

2. Fark T, Hummel C, Hähner A, et al. Characteristics of taste disorders. Eur Arch Otorhinolaryngol 2013;270:1855-60.

3. Imoscopi A, Inelmen EM, Sergi G, et al. Taste loss in the elderly: epidemiology, causes and consequences. Aging Clin Exp Res 2012;24:570-9.

4. Schiffman SS. Taste and smell losses in normal aging and disease. JAMA 1997;278:1357-62.

5. Suter VGA, Negoias $\mathrm{S}$, Friedrich $\mathrm{H}$, et al. Gustatory function and taste perception in patients with oral lichen planus and tongue involvement. Clin Oral Investig 2017;21:957-64.

6. Heiser C, Landis BN, Giger R, et al. Taste disturbance following tonsillectomy--a prospective study. Laryngoscope 2010;120:2119-24.

7. Saglam O, Altundag A, Cayonu M, et al. Olfactory and gustatory functions after anterior palatoplasty in patients with primary snoring. Otolaryngol Head Neck Surg 2016;154:1155-60.

8. Dazzi F, Nitto SD, Zambetti G, et al. Alterations of the olfactorygustatory functions in patients with eating disorders. Eur Eat Disord Rev 2013;21:382-5.

9. Tomita H, Ikeda M, Okuda Y. Basis and practice of clinical taste examinations. Auris Nasus Larynx 1986;13 Suppl 1(Suppl 1):S1-S15.

10. Wu S, Chen J. Using pullulan-based edible coatings to extend shelflife of fresh-cut 'Fuji' apples. Int J Biol Macromol 2013;55:254-7.

11. Neta NS, Teixeira JA, Rodrigues LR. Sugar ester surfactants: enzymatic synthesis and applications in food industry. Crit Rev Food Sci Nutr 2015;55:595-610.

12. Travers SP, Nicklas K. Taste bud distribution in the rat pharynx and larynx. Anat Rec 1990;227:373-9.

13. Ferguson J, Addo HA, Johnson BE, et al. Quinine induced photosensitivity: clinical and experimental studies. $\mathrm{Br} J$ Dermatol 1987;117:631-40.

14. Perdomo J, Yan F, Ahmadi Z, et al. Quinine-induced thrombocytopenia: drug-dependent GPIb/IX antibodies inhibit megakaryocyte and proplatelet production in vitro. Blood 2011;117:5975-86.

15. Mueller C, Kallert S, Renner B, et al. Quantitative assessment of gustatory function in a clinical context using impregnated "taste strips". Rhinology 2003;41:2-6.

16. Landis BN, Welge-Luessen A, Brämerson A, et al. "Taste Strips" - a rapid, lateralized, gustatory bedside identification test based on impregnated filter papers. J Neurol 2009;256:242-8.

17. Manzi B, Hummel T. Intensity of regionally applied tastes in relation to administration method: an investigation based on the "taste strips" test. Eur Arch Otorhinolaryngol 2014;271:411-5.

18. Ahne G, Erras A, Hummel T, et al. Assessment of gustatory function by means of tasting tablets. Laryngoscope 2000;110:1396-401.

19. Kasahara T, Yamashita S, Nimura H, et al. Newly designed gustatory test based on the number of chewing strokes required for recognition of the taste. J Prosthodont Res 2012;56:210-5.

20. Smutzer G, Lam S, Hastings $L$, et al. A test for measuring gustatory function. Laryngoscope 2008;118:1411-6.

21. Cecchini MP, Osculati F, Ottaviani S, et al. Taste performance in Parkinson's disease. J Neural Transm 2014;121:119-22.

22. Hill CA, Dang S, Beach M, et al. A retrospective cohort study of glossopharyngeal nerve taste in children with recurrent acute tonsillitis. Otolaryngol Head Neck Surg 2017;156:189-93.

23. Matsuo R. Role of saliva in the maintenance of taste sensitivity. Crit Rev Oral Biol Med 2000;11:216-29.

24. Lindemann B. Receptor seeks ligand: on the way to cloning the molecular receptors for sweet and bitter taste. Nat Med 1999;5:381-2.

25. Chaudhari N, Roper SD. The cell biology of taste. J Cell Biol 2010;190:285-96. 